Supplement of Biogeosciences, 16, 2961-2981, 2019

https://doi.org/10.5194/bg-16-2961-2019-supplement

(C) Author(s) 2019. This work is distributed under

the Creative Commons Attribution 4.0 License.

(c) (1)

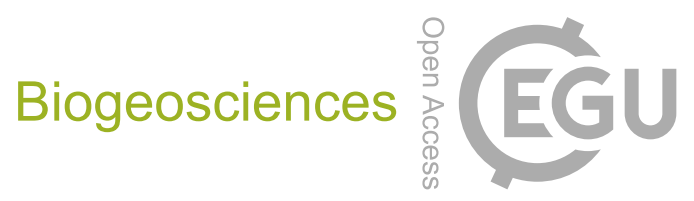

Supplement of

\title{
Highly branched isoprenoids for Southern Ocean sea ice reconstructions: a pilot study from the Western Antarctic Peninsula
}

Maria-Elena Vorrath et al.

Correspondence to: Maria-Elena Vorrath (maria-elena.vorrath@awi.de)

The copyright of individual parts of the supplement might differ from the CC BY 4.0 License. 
Supplementary Material
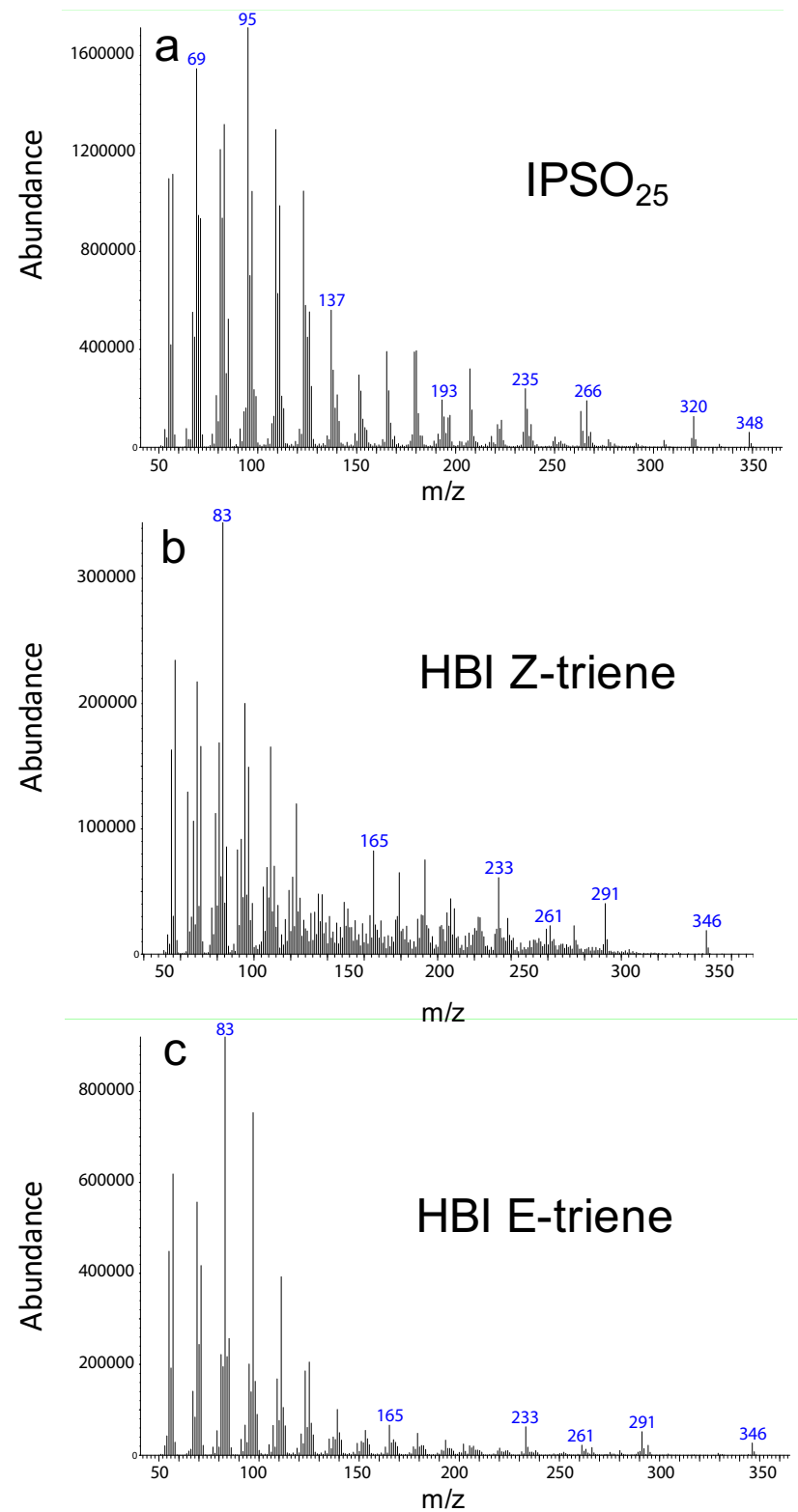

Supplement S1: Examples of mass spectra of IPSO $_{25}(\mathrm{~m} / \mathbf{z} 348)$, HBI Z-triene and E-triene (both m/z 346) obtained from surface sediments in the study area. 


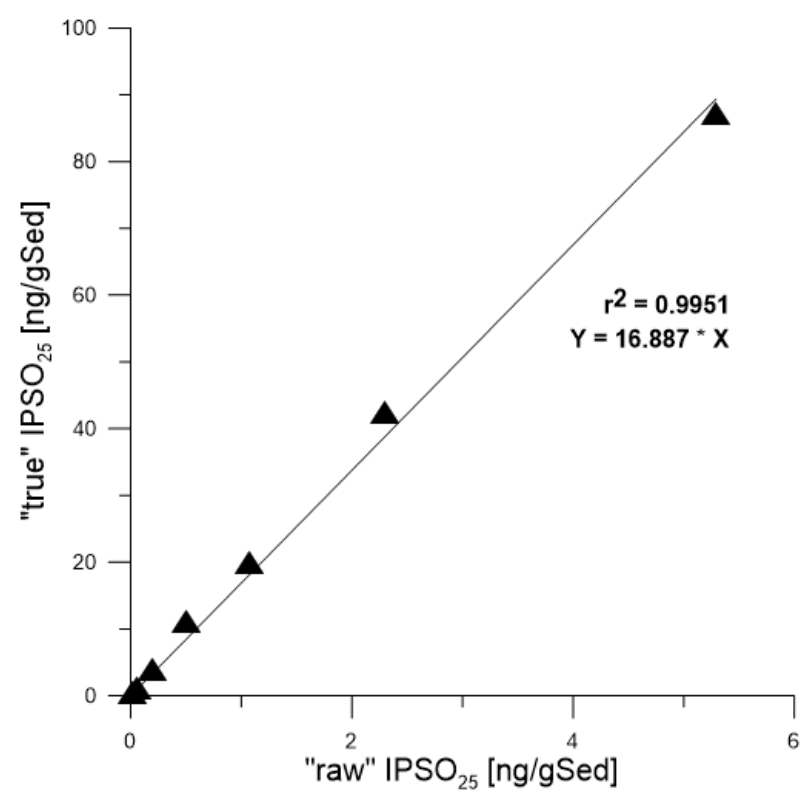

Supplement S2: Example calibration curve for the quantification of IPSO ${ }_{25}$. Different (true) IPSO $_{25}$ concentrations determined via gas chromatography-flame ionization are plotted against (raw) IPSO$_{25}$ concentrations determined via gas chromatography-mass spectrometry using selected ion monitoring $(\mathbf{m} / \mathbf{z}$ 348). The instrumental response factor is obtained from the regression line. 